Available online at http://iddtonline.info

Journal of Drug Delivery and Therapeutics

Open access to Pharmaceutical and Medical research

(c) 2014, publisher and licensee JDDT, This is an Open Access article which permits unrestricted noncommercial use, provided the original work is properly cited

\title{
RESEARCHARTICLE
}

\section{ANTI-TUBERCULOSIS DRUG RESISTANCE IN ETHIOPIA: A MATA- ANALYSIS}

\author{
Gebremichael Lemlem Gebremedhin $^{1 *}$, Fanta Biruk Sintayehu ${ }^{2}$, Abay Solomon Mequanente ${ }^{3}$, Subas Chandra Dinda ${ }^{4}$ \\ ${ }^{1}$ Pharmacology and Toxicology course and research unit, Department of pharmacy, college of health sciences, Mekelle \\ University
}

${ }^{2}$ Pharmacognosy Course and Research Unit, Department of Pharmacy, College of Health Sciences, Mekelle University

${ }^{3}$ Pharmacology department, Faculty of Medicine, Addis Ababa University

${ }^{4}$ Department of Pharmaceutics, C.H.S., Mekelle University, Mekelle, Ethiopia.

\begin{abstract}
Tuberculosis is one of the most dangers of health in the world. Ethiopia ranked seventh from the 22 high burden counties in the world. The main problem is development of resistance to the major anti-tuberculosis drugs actually increasing in Ethiopia. The aim was to review studies done on anti-tuberculosis drug resistance in Ethiopia. Literatures were searched for published articles on anti-tuberculosis drug resistance using the combination of terms; resistance, anti-tuberculosis and Ethiopia. Fifteen studies done in different parts of Ethiopia from 1978-2005 G.C were retrieved without restriction of place \& design of study. The primary resistance of the fifteen studies done in various parts of Ethiopia (Addis Ababa, Harar, Bahir Dar, Sidamo, Arsi, and Hosanna) from1978-2005 G.C showed: Isoniazid (H) 1.9\%-21.4\%, Streptomycin (S) 1.9\%-26\%, Rifampicin (R) 0\%$1.9 \%$, Ethambutol (E) $0 \%-6.3 \%$, Thiacetazone (T) $2.2 \%-6.3 \%$, H+S $1.9 \%-26 \%$, H+T $0 \%-4.4 \%$, S+T $0 \%-1.8 \%$, H+R $0 \%-$ $1.1 \%, \mathrm{~S}+\mathrm{R} 0 \%-0.7 \%, \mathrm{R}+\mathrm{T} 0 \%-0.4 \%, \mathrm{H}+\mathrm{E} 0 \%-0.9 \%, \mathrm{~S}+\mathrm{E} 0 \%-0.6 \%, \mathrm{H}+\mathrm{S}+\mathrm{T} 0 \%-2.4 \%, \mathrm{H}+\mathrm{S}+\mathrm{R} 0 \%-1.1 \%, \mathrm{H}+\mathrm{T}+\mathrm{R} 0 \%-0.4 \%$, $\mathrm{H}+\mathrm{S}+\mathrm{E} 0 \%-1.7 \%, \mathrm{R}+\mathrm{H}+\mathrm{T}+\mathrm{S} 0 \%-0.6 \%$ and Multi Drug Resistance 0\%-1.3\%.Acquired drug resistance: $\mathrm{H}$ 5.3\%-66.7\%, S $1.2 \%-46 \%$, R $0 \%-12 \%$, E $0 \%-5.6 \%$, T0\%-29\%, H+T 0\%-20\%, H+S 4.8\%- 28\%, R+H 0\%-8\%, R+S 0\%-3.5\%, S+T 0\%$2.3 \%, \mathrm{H}+\mathrm{E} 0 \%-3.6 \%, \mathrm{R}+\mathrm{E} 0 \%-5.6 \%, \mathrm{~S}+\mathrm{E} 0 \%-11.2 \%, \mathrm{H}+\mathrm{S}+\mathrm{T} 0 \%-16 \%, \mathrm{R}+\mathrm{S}+\mathrm{T} 0 \%-2.3 \%, \mathrm{R}+\mathrm{S}+\mathrm{H} 0 \%-4 \%, \mathrm{H}+\mathrm{S}+\mathrm{E} 0 \%-$ $3.6 \%, \mathrm{H}+\mathrm{R}+\mathrm{E} 0 \%-3.6 \%, \mathrm{H}+\mathrm{R}+\mathrm{S}+\mathrm{E}$ 0\%-14.3\% and Multi Drug Resistance 0\%-26.3\%. It can be concluded that resistance to the anti-tuberculosis drugs is increasing. National level drug resistance survey is recommended to design policies and strategies to prevent increase of drug resistance.

Key words: Resistance, tuberculosis, anti-tuberculosis drugs and Ethiopia.
\end{abstract}

\section{INTRODUCTION}

Tuberculosis (TB) is the most frequent cause of death. About 8.4 million people develop active tuberculosis every year and 2.3 million die of it. It is estimated that 200 million additional people are at risk of developing the disease in the next 20 years, if the current trends are conserved. $^{1}$

Report from 183 countries shows that there are 3.8 million cases of TB (62 per 100,000 populations) around the world. Nearly $42 \%$ of these cases are sputum smear positive. The global incidence of TB is growing at $0.4 \%$ each year. More rapid growth was observed in subSaharan Africa due to the spread of HIV and in countries of the former Soviet Union. Treatment success under Directly Observed Treatment Short course (DOTS) for the 2000 cohort was $82 \%$ on average and it is below the average $(72 \%)$ for African region. ${ }^{2}$ The DOTS strategy has been the principal response to the global TB epidemic for the past decades. DOTS programmes between the start of 1995 and the end of 2001 diagnosed more than ten million patients. Of these over five million were smear positive. ${ }^{2}$ By the end of 2001, DOTS had been adopted by 155 countries and was available to $61 \%$ (c) 2011-14, JDDT. All Rights Reserved of the world Habitants. Ethiopia's National Tuberculosis and Leprosy Control Program (NTLCP) began to implement DOTS in two zones (Arsi and Bale) in 1991. In 2007, WHO reported that DOTS coverage reached $95 \%$ of the population. However, while treatment is integrated into general health services and due to the limited health infrastructure in the country, only approximately 60 to $70 \%$ of the population has access to DOTS services. The DOTS detection rate remains low, at $28 \%$, compared with world health organization's (WHO's) target of 70\% detection. The limited diagnostic capacity for $\mathrm{TB}$ in the country remains a challenge to improving case detection rates. The treatment success rate is close to the $85 \%$ target set by WHO; after falling from $80 \%$ in 2000 to $70 \%$ in 2003 , it rose to $84 \%$ in $2007 .^{3}$

\section{*Corresponding author:}

Gebremichael Lemlem Gebremedhin Email:Lemlemgatt2006@gmail.com/lemlemgd@yahoo.com Phone number: +251-911-54-41-98 
The burden of TB in Ethiopia is one of the highest in the world. There are 22 countries that are labelled by WHO to carry $80 \%$ of the estimated number of all new TB cases(all forms) of the world TB and Ethiopia ranks seventh among the world's 22 high-burden tuberculosis countries and third from African countries. ${ }^{4,5}$ In Ethiopia, According to the ministry of health $(\mathrm{MOH})$ hospital statistics data, tuberculosis is the leading cause of morbidity, the third cause of hospital admission (after deliveries and malaria), and the second cause of death (after malaria). According to the WHO's Global TB Report 2009, the country had an estimated 314,267 TB cases in 2007, with an estimated incidence rate of 378 cases per 100,000 population with a mortality rate of 79deaths/100,000 population/year. ${ }^{3}$

Tuberculosis is caused by mycobacterium primarily mycobacterium tuberculosis in human. It is broadly classified in to: Pulmonary TB which is infectious and the most frequent form of the disease, accounts for $85 \%$ of all TB cases and Extra-pulmonary TB that results from spread of TB to other organs accounting $14 \%$ of all TB cases in the world. TB can affect any part of the body 6,7

The major problem with treatment of $\mathrm{TB}$ is the development of resistance (decrease in susceptibility of sufficient degree from a wild strain that has never been exposed to the drug).$^{8,}{ }^{9,10}$ There are two types of resistance: primary resistance that is resistance to any drug is developed by some strain without prior exposure to that drug and acquired resistance :mainly man made problem for development of resistance that is caused by non-compliance by the patient and by medical practitioners that include long period of treatment (6-12 months), complex drug prescription, costs of treatment, long waits in health facilities, belief of the patient on the drug and health professionals, mental illness, use of alcohol, substance abuse, and homelessness. ${ }^{11}$

The numbers of TB cases are also increasing as Ethiopia's HIV/AIDS epidemic expands; while $16 \%$ of notified TB patients tested for HIV, $40 \%$ are HIV positive. The level of multidrug-resistant TB (MDR-TB) (TB that is resistant at least to INH and RMP) among new TB cases is estimated at $20 \%$. Five thousand nine hundred seventy nine cases of MDR-TB were reported in $2007 .^{3}$

To prevent the development of resistance combination therapy is used in TB treatment in two phases: intensive phase and continuation phase. The drugs used for treatment are grouped in to two depending on availability, efficacy, cost and toxicity: first line drugs, (isoniazide $(\mathrm{INH})(\mathrm{H}), \quad$ rifampicin (RMP) (R), pyraziniamide (PZM) (Z), ethambutol (EMB) (E) and streptomycin (STM) (S)) ${ }^{12,13}$ and second line drugs, Aminoglycosides: e.g., amikacin, kanamycin; Polypeptides: e.g., capreomycin, viomycin, enviomycin; Fluoroquinolones: e.g., ciprofloxacin, levofloxacin, moxifloxacin; Thioamides: e.g. ethionamide, prothionamide; cycloserine (the only antibiotic in its class); p-aminosalicylic acid. ${ }^{14}$ The aim of this study is to review all the studies done on anti-tuberculosis drug resistance in Ethiopia.

\section{METHODOLOGY}

PUBMED, MEDLINE and HINARI were searched for published articles on anti-tuberculosis drug resistance using the combination of terms; anti-tuberculosis, resistance, and Ethiopia. National journals were also searched manually in different libraries; Ethiopian medical journals, Ethiopian pharmaceutical journals and Ethiopian journal of health development for antituberculosis drug resistance in Ethiopia without restriction of place, year and design of study.

Fifteen studies done in different parts of Ethiopia (Addis Ababa, Harar, Bahirdar, Arsi, Sidamo, and Hosanna) from 1978-2005 G.C regarding anti-TB drug resistance were retrieved. The results of the different studies were obtained from published national journals; Ethiopian medical journals, Ethiopian pharmaceutical journals, Ethiopian journal of health development and some unpublished MSC thesis from Addis Ababa University. The results of the different studies done in different period and in various parts of Ethiopia were summarized in the form of tables and figures. The different drugs used in various studies were included according to the year of study. In this review; the number of isolates, year of study, study site and the percentage of resistance to the anti-tuberculosis drugs used in that study were also included. Any drug resistance, according to this review, means resistance to one or more anti-tuberculosis drugs. Re-treatment cases were considered as acquired resistance in this review.

\section{RESULTS}

Results of the various studies done in different parts of Ethiopia were summarized according to their year of study, the drugs included, the number of strains isolated and the percentage of resistance for single drug and drug combinations. The percentages of resistance (primary and acquired, any drug and more than two drugs) of each included drug were summarized in tables and figures.

The Fifteen studies done in different parts of Ethiopia (Addis Ababa (A.A), Harar, Bahir Dar, Sidamo, Arsi, and Hosanna) from1978-2005 G.C showed that the primary resistance of Isoniazid ranges from $1.9 \%$ to $21.4 \%$, Streptomycin from $1.9 \%$ to $26 \%$, Rifampicin from $0 \%$ to $1.9 \%$, Ethambutol from $0 \%$ to $6.3 \%$, Thiacetazone from $2.2 \%$ to $6.3 \%, \mathrm{H}+\mathrm{S}$ from $1.9 \%$ to $26 \%, \mathrm{H}+\mathrm{T}$ from $0 \%$ to $4.4 \%, \mathrm{~S}+\mathrm{T}$ from $0 \%$ to $1.8 \%$, $\mathrm{H}+\mathrm{R}$ from $0 \%$ to $1.1 \%, \mathrm{~S}+\mathrm{R}$ from $0 \%$ to $0.7 \%, \mathrm{R}+\mathrm{T}$ from $0 \%$ to $0.4 \%, \mathrm{H}+\mathrm{E}$ from $0 \%$ to $0.9 \%, \mathrm{~S}+\mathrm{E}$ from $0 \%$ to $0.6 \% \mathrm{H}+\mathrm{S}+\mathrm{T}$ from $0 \%$ to $2.4 \%, \mathrm{H}+\mathrm{S}+\mathrm{R}$ from $0 \%$ to $1.1 \%, \mathrm{H}+\mathrm{T}+\mathrm{R}$ from $0 \%$ to $0.4 \%, \mathrm{H}+\mathrm{S}+\mathrm{E}$ from $0 \%$ to $1.7 \%$, for $\mathrm{R}+\mathrm{H}+\mathrm{T}+\mathrm{S}$ from $0 \%$ to $0.6 \%$ and MDR ranges from $0 \%$ to $1.3 \%$ (Table-1). 
Table 1: Summary of primary drug resistance in different cities of ETHIOPIA, 1981-2005 G.C.

\begin{tabular}{|c|c|c|l|c|c|c|}
\hline $\begin{array}{c}\text { Year } \\
\text { of } \\
\text { study }\end{array}$ & $\begin{array}{c}\text { Study } \\
\text { site }\end{array}$ & $\begin{array}{c}\text { No. of } \\
\text { Isolates }\end{array}$ & \multicolumn{1}{|c|}{ Resistance (\%) } & $\begin{array}{c}\text { MDR } \\
\%\end{array}$ & Study type & Reference \\
\hline 1981 & A.A & 182 & $\mathrm{H}(15), \mathrm{S}(5), \mathrm{T}(4), \mathrm{R}(1), \mathrm{H}+\mathrm{S}(5), \mathrm{H}+\mathrm{T}(4), \mathrm{H}+\mathrm{S}+\mathrm{T}(2)$ & 0 & Retrospective & 16 \\
\hline 1986 & $\begin{array}{c}\text { A.A/ } \\
\text { Harar }\end{array}$ & 276 & $\begin{array}{l}\mathrm{H}(11.9), \mathrm{S}(9.4), \mathrm{T}(2.2), \mathrm{R}(1.1), \mathrm{H}+\mathrm{S}(6.1), \mathrm{S}+\mathrm{T}(1.8), \\
\mathrm{H}+\mathrm{R}(1.1), \mathrm{S}+\mathrm{R}(0.7), \mathrm{R}+\mathrm{T}(0.4), \mathrm{H}+\mathrm{S}+\mathrm{T}(1.4), \\
\mathrm{H}+\mathrm{S}+\mathrm{R}(1.1), \mathrm{H}+\mathrm{T}+\mathrm{R}(0.4)\end{array}$ & 1.1 & Prospective & 17 \\
\hline 1989 & Sidamo & 104 & $\begin{array}{l}\mathrm{H}(1.9), \mathrm{S}(1.9), \mathrm{R}(0), \mathrm{E}(0), \mathrm{H}+\mathrm{S}(3.8), \mathrm{H}+\mathrm{R}(0), \\
\mathrm{R}+\mathrm{S}(0), \mathrm{R}+\mathrm{E}(0), \mathrm{H}+\mathrm{E}(0)\end{array}$ & 0 & $\begin{array}{c}\text { Cross- } \\
\text { sectional }\end{array}$ & 18 \\
\hline 1994 & A.A & 167 & $\begin{array}{l}\mathrm{H}(8.4), \mathrm{S}(10.2), \mathrm{T}(6.0), \mathrm{R}(1.8), \mathrm{E}(0), \mathrm{H}+\mathrm{T}(2.4), \\
\mathrm{S}+\mathrm{T}(0.6), \mathrm{R}+\mathrm{H}(0.6), \mathrm{R}+\mathrm{S}(0.6), \mathrm{S}+\mathrm{T}+\mathrm{H}(2.4), \\
\mathrm{R}+\mathrm{S}+\mathrm{T}+\mathrm{H}(0.6)\end{array}$ & 0.6 & $\begin{array}{c}\text { Cross- } \\
\text { sectional }\end{array}$ & 20 \\
\hline $1994 / 5$ & Harar & 252 & $\begin{array}{l}\mathrm{H}(21.4), \mathrm{S}(20.2), \mathrm{T}(6.3), \mathrm{R}(1.6), \mathrm{E}(6.3), \mathrm{H}+\mathrm{T}(4.4), \\
\mathrm{R}+\mathrm{H}(0.4), \mathrm{S}+\mathrm{H}(9.9), \mathrm{S}+\mathrm{T}(1.2), \mathrm{R}+\mathrm{S}(0.4), \\
\mathrm{H}+\mathrm{T}+\mathrm{S}(1.6), \mathrm{R}+\mathrm{S}+\mathrm{T}(0)\end{array}$ & 0.4 & $\begin{array}{c}\text { Cross- } \\
\text { sectional }\end{array}$ & 21 \\
\hline 1998 & Arsi & 176 & $\begin{array}{l}\mathrm{H}(2.3), \mathrm{S}(11.4), \mathrm{T}(1.1), \mathrm{R}(0) \mathrm{E}(0), \mathrm{H}+\mathrm{S}(2.8), \\
\mathrm{H}+\mathrm{R}(0), \mathrm{H}+\mathrm{S}+\mathrm{T}(0.5)\end{array}$ & 0 & $\begin{array}{c}\text { Cross- } \\
\text { sectional }\end{array}$ & 24 \\
\hline 1998 & A.A & 179 & $\mathrm{H}(8.4), \mathrm{S}(7.3), \mathrm{E}(0), \mathrm{R}(0.6)$ & 0.6 & $\begin{array}{c}\text { Cross- } \\
\text { sectional }\end{array}$ & 38 \\
\hline 2001 & A.A & 103 & $\begin{array}{l}\mathrm{H}(8.7), \mathrm{S}(7.8), \mathrm{R}(1.9), \mathrm{E}(0.9), \mathrm{H}+\mathrm{S}(1.9), \mathrm{H}+\mathrm{E}(0.9), \\
\mathrm{E}+\mathrm{R}(0), \mathrm{H}+\mathrm{R}+\mathrm{S}(0.9)\end{array}$ & 0.9 & $\begin{array}{c}\text { Cross- } \\
\text { sectional }\end{array}$ & 25 \\
\hline 2001 & Bahirdar & 76 & $\mathrm{H}(3.9), \mathrm{S}(15.8), \mathrm{E}(0), \mathrm{R}(1.3), \mathrm{H}+\mathrm{R}+\mathrm{S}(1.3)$ & 1.3 & $\begin{array}{c}\text { Cross- } \\
\text { sectional }\end{array}$ & 26 \\
\hline 2002 & Hosanna & 27 & $\mathrm{H}(20), \mathrm{S}(13.3), \mathrm{E}(0), \mathrm{R}(0), \mathrm{H}+\mathrm{S}(7.4)$ & $\begin{array}{c}\text { Cross- } \\
\text { sectional }\end{array}$ & 27 \\
\hline $2004 / 5$ & A.A & 73 & $\mathrm{H}(5.5), \mathrm{R}(1.4), \mathrm{S}(26), \mathrm{E}(2.7), \mathrm{S}+\mathrm{H}(26), \mathrm{H}+\mathrm{S}+\mathrm{E}(1.4)$ & 0 & $\begin{array}{c}\text { Cross- } \\
\text { sectional }\end{array}$ & 29 \\
\hline $2004 / 5$ & A.A & 173 & $\begin{array}{l}\mathrm{H}(13.3), \mathrm{S}(16.2), \mathrm{R}(1.2), \mathrm{E}(3.5), \mathrm{H}+\mathrm{S}(7.5), \\
\mathrm{S}+\mathrm{E}(0.6), \mathrm{H}+\mathrm{R}+\mathrm{S}(0.6), \mathrm{H}+\mathrm{S}+\mathrm{E}(1.7)\end{array}$ & 0.6 & $\begin{array}{c}\text { Cross- } \\
\text { sectional }\end{array}$ & 30 \\
\hline
\end{tabular}

Table 2: Summary of acquired drug resistance in different cities of ETHIOPIA, 1978-2002 G.C.

\begin{tabular}{|c|c|c|c|c|c|c|}
\hline $\begin{array}{l}\text { Year of } \\
\text { study }\end{array}$ & Study site & $\begin{array}{l}\text { No. of } \\
\text { Isolates }\end{array}$ & Resistance (\%) & $\begin{array}{c}\text { MDR } \\
\%\end{array}$ & Study type & Ref \\
\hline 1978 & $\begin{array}{l}\text { Addis } \\
\text { Ababa }\end{array}$ & 184 & $\begin{array}{l}\mathrm{H}(46), \mathrm{S}(46), \mathrm{T}(29), \mathrm{H}+\mathrm{T}(20) \\
\mathrm{H}+\mathrm{S}(28), \mathrm{H}+\mathrm{S}+\mathrm{T}(16)\end{array}$ & 0 & Cross-sectional & 15 \\
\hline $1994 / 5$ & Harar & 86 & $\begin{array}{l}\mathrm{H}(44.2), \mathrm{S}(31.4), \mathrm{R}(0), \mathrm{T}(8.1), \\
\mathrm{E}(0), \mathrm{H}+\mathrm{T}(5.8), \mathrm{R}+\mathrm{H}(3.5), \\
\mathrm{H}+\mathrm{S}(23.2), \mathrm{S}+\mathrm{T}(2.3), \\
\mathrm{R}+\mathrm{S}(3.5), \mathrm{H}+\mathrm{T}+\mathrm{S}(2.3), \\
\mathrm{R}+\mathrm{S}+\mathrm{T}(2.3), \mathrm{R}+\mathrm{S}+\mathrm{H}(0)\end{array}$ & 3.5 & Cross-sectional & 21 \\
\hline 1996 & $\begin{array}{l}\text { Addis } \\
\text { Ababa }\end{array}$ & 113 & $\begin{array}{l}\mathrm{H}(47), \mathrm{S}(31), \mathrm{R}(11.5), \mathrm{E}(2.6) \\
\mathrm{H}+\mathrm{S}(22), \mathrm{H}+\mathrm{E}(0.9), \mathrm{H}+\mathrm{R}(8) \\
\mathrm{H}+\mathrm{S}+\mathrm{R}(3.5), \mathrm{H}+\mathrm{S}+\mathrm{E}(1.8)\end{array}$ & 11.5 & Cross-sectional & 22 \\
\hline 1998 & Arsi & 19 & $\begin{array}{l}\mathrm{H}(5.3), \mathrm{R}(0), \mathrm{S}(10.5), \mathrm{T}(0) \\
\mathrm{E}(0), \mathrm{H}+\mathrm{S}(15.7), \mathrm{H}+\mathrm{R}(0) \\
\mathrm{H}+\mathrm{S}+\mathrm{T}(0)\end{array}$ & 0 & Cross-sectional & 24 \\
\hline 1998 & $\begin{array}{l}\text { Addis } \\
\text { Ababa }\end{array}$ & 107 & $\begin{array}{l}\mathrm{H}(44), \mathrm{S}(28), \mathrm{R}(12), \mathrm{E}(2) \\
\mathrm{H}+\mathrm{S}(19), \mathrm{H}+\mathrm{R}(8), \mathrm{H}+\mathrm{R}+\mathrm{S}(4)\end{array}$ & 12 & Cross-sectional & 19 \\
\hline 2001 & $\begin{array}{l}\text { Addis } \\
\text { Ababa }\end{array}$ & 18 & $\begin{array}{l}\mathrm{H}(5.6), \mathrm{R}(5.6), \mathrm{E}(5.6), \mathrm{S}(5.6) \\
\mathrm{H}+\mathrm{S}(5.6), \mathrm{H}+\mathrm{E}(0), \mathrm{R}+\mathrm{E}(5.6) \\
\mathrm{H}+\mathrm{R}+\mathrm{S}(0)\end{array}$ & 0 & Cross-sectional & 25 \\
\hline $2001 / 2$ & $\begin{array}{l}\text { Addis } \\
\text { Ababa }\end{array}$ & 84 & $\begin{array}{l}\mathrm{H}(7.1), \mathrm{E}(2.4), \mathrm{S}(1.2), \mathrm{H}+\mathrm{R}(2.4 \mathrm{H}+\mathrm{S}(4.8), \mathrm{H} \\
+\mathrm{E}(3.6), \mathrm{R}+\mathrm{E}(3.6), \mathrm{S}+\mathrm{E}(11.2), \mathrm{H}+\mathrm{R}+\mathrm{S}(6), \\
\mathrm{H}+\mathrm{R}+\mathrm{E}(3.6), \mathrm{H}+\mathrm{S}+\mathrm{E}(3.6) \\
\mathrm{H}+\mathrm{R}+\mathrm{S}+\mathrm{E}(14.3)\end{array}$ & 26 & Cross-sectional & 28 \\
\hline 2002 & Hosanna & 3 & $\begin{array}{l}\mathrm{H}(66.7), \mathrm{S}(0), \mathrm{E}(0), \mathrm{R}(0) \\
\mathrm{H}+\mathrm{R}(0), \mathrm{S}+\mathrm{R}(0), \mathrm{R}+\mathrm{E}(0)\end{array}$ & 0 & Cross-sectional & 27 \\
\hline
\end{tabular}


The acquired resistance of Isoniazid ranges from 5.3\% to $66.7 \%$, Streptomycin from $1.2 \%$ to $46 \%$, Rifampicin from $0 \%$ to $12 \%$, Ethambutol from $0 \%$ to $5.6 \%$, Thiacetazone from $0 \%$ to $29 \%, \mathrm{H}+\mathrm{T}$ from $0 \%$ to $20 \%$, $\mathrm{H}+\mathrm{S}$ from $4.8 \%$ to $28 \%, \mathrm{R}+\mathrm{H}$ from $0 \%$ to $8 \%, \mathrm{R}+\mathrm{S}$ from $0 \%$ to $3.5 \%, \mathrm{~S}+\mathrm{T}$ from $0 \%$ to $2.3 \%, \mathrm{H}+\mathrm{E}$ from $0 \%$ to $3.6 \%, \mathrm{R}+\mathrm{E}$ from $0 \%$ to $5.6 \%, \mathrm{~S}+\mathrm{E}$ from $0 \%$ to $11.2 \%$, $\mathrm{H}+\mathrm{S}+\mathrm{T}$ from $0 \%$ to $16 \%, \mathrm{R}+\mathrm{S}+\mathrm{T}$ from $0 \%$ to $2.3 \%$ $\mathrm{R}+\mathrm{S}+\mathrm{H}$ from $0 \%$ to $4 \%, \mathrm{H}+\mathrm{S}+\mathrm{E}$ from $0 \%$ to $3.6 \%$, $\mathrm{H}+\mathrm{R}+\mathrm{E}$ from $0 \%$ to $3.6 \%$, for $\mathrm{H}+\mathrm{R}+\mathrm{S}+\mathrm{E}$ ranges from
$0 \%$ to $14.3 \%$ and MDR ranges from $0 \%$ to $26.3 \%$ (Table-2).

The study carried in Addis Ababa TB center in 1978 to asses acquired drug resistance in 184 isolates of $M$. tuberculosis showed that the resistance to isoniazid (INH) and streptomycin (STM) was 46\% each. Twenty nine percent was for thiacetazone (THA). Double drug resistance ranged 20-28\% (INH+THA=20\% and $\mathrm{INH}+\mathrm{STM}=28 \%$ ) and triple drug resistance was $15 \%$ $\left(\right.$ INH+THA+STM) $\left(\right.$ Table-3andTable-4). ${ }^{15}$

Table 3: SUMMARY OF ACQUIRED RESISTANCE OF ANY DRUG IN DIFFERENT CITIES OF ETHIOPIA, 1994/5-2002 G.C.

\begin{tabular}{|c|c|c|c|c|c|}
\hline Year of study & Study site & No. of isolates & Any drug resistance $\%$ & Study type & Reference \\
\hline $1994 / 95$ & Harar & 86 & 51.2 & Cross-sectional & 21 \\
\hline 1996 & Addis Ababa & 113 & 51 & Cross-sectional & 22 \\
\hline 1998 & Arsi & 19 & 31.6 & Cross-sectional & 24 \\
\hline 1998 & Addis Ababa & 107 & 50 & Cross-sectional & 19 \\
\hline 2001 & Addis Ababa & 18 & 33.6 & Cross-sectional & 25 \\
\hline $2001 / 2$ & Addis Ababa & 84 & 53.6 & Cross-sectional & 28 \\
\hline 2002 & Hosanna & 3 & 66.7 & Cross-sectional & 27 \\
\hline
\end{tabular}

Table 4: SUMMARY OF ACQUIRED RESISTANCE OF MORE THAN TWO DRUGS IN DIFFERENT CITIES OF ETHIOPIA, 1978-2002 G.C.

\begin{tabular}{|c|c|c|c|c|c|}
\hline Year of study & Study site & $\begin{array}{c}\text { No. of } \\
\text { isolates }\end{array}$ & $\begin{array}{c}\text { More than two drugs } \\
\text { resistance (\%) }\end{array}$ & Study type & Reference \\
\hline 1978 & Addis Ababa & 184 & 64 & Cross-sectional & 15 \\
\hline $1994 / 5$ & Harar & 86 & 42.9 & Cross-sectional & 21 \\
\hline 1996 & Addis Ababa & 113 & 36.2 & Cross-sectional & 22 \\
\hline 1998 & Arsi & 19 & 15.7 & Cross-sectional & 24 \\
\hline 1998 & Addis Ababa & 107 & 31 & Cross-sectional & 19 \\
\hline 2001 & Addis Ababa & 18 & 11.2 & Cross-sectional & 25 \\
\hline $2001 / 2$ & Addis Ababa & 84 & 42.9 & Cross-sectional & 28 \\
\hline 2002 & Hosanna & 3 & 0 & Cross-sectional & 27 \\
\hline
\end{tabular}

In 1981 a study was done in 182 isolates from newly diagnosed TB patients of Addis Ababa in Addis Ababa TB center. Of the 182 isolates $15 \%$ were INH resistant,
5\% STM resistant, 4\% THA resistant, 1\% RMP resistant, $5 \%$ were resistant to INH+STM, $4 \%$ to INH+THA and $2 \%$ to INH+THA+ STM (Table-1,5\&6). ${ }^{16}$

Table 5: SUMMARY OF PRIMARY RESISTANCE OF ANY DRUG IN DIFFERENT CITIES OF ETHIOPIA, 1981-2005 G.C.

\begin{tabular}{|c|c|c|c|c|c|}
\hline Year of study & Study site & $\begin{array}{c}\text { No. of } \\
\text { isolates }\end{array}$ & $\begin{array}{c}\text { Any drug } \\
\text { resistance \% }\end{array}$ & Study type & Reference \\
\hline 1981 & Addis Ababa & 182 & 14.8 & Retrospective & 16 \\
\hline 1986 & Addis Ababa/ Harar & 276 & 15.2 & Prospective & 17 \\
\hline 1989 & Sidamo & 104 & 7.6 & Cross-sectional & 18 \\
\hline 1994 & Addis Ababa & 167 & 15.6 & Cross- sectional & 20 \\
\hline $1994 / 5$ & Harar & 252 & 32.5 & Cross-sectional & 21 \\
\hline 1998 & Arsi & 176 & 19.5 & Cross-sectional & 24 \\
\hline 1998 & Addis Ababa & 179 & 12.9 & Cross-sectional & 38 \\
\hline 2001 & Addis Ababa & 103 & 14.6 & Cross-sectional & 25 \\
\hline 2001 & Bahir Dar & 76 & 18.4 & Cross-sectional & 26 \\
\hline 2002 & Hosanna & 27 & 22.2 & Cross-sectional & 27 \\
\hline $2004 / 5$ & Addis Ababa & 73 & 17.8 & Cross-sectional & 29 \\
\hline $2004 / 5$ & Addis Ababa & 173 & 21.4 & Cross-sectional & 30 \\
\hline
\end{tabular}


Table 6: SUMMARY OF PRIMARY RESISTANCE OF MORE THAN TWO DRUGS IN DIFFERENT CITIES OF ETHIOPIA, 1981-2005 G.C.

\begin{tabular}{|c|c|c|c|c|c|}
\hline Year of study & Study site & $\begin{array}{c}\text { No. of } \\
\text { isolates }\end{array}$ & $\begin{array}{c}\text { More than two drugs } \\
\text { resistance (\%) }\end{array}$ & Study type & Reference \\
\hline 1981 & Addis Ababa & 182 & 11 & Retrospective & 16 \\
\hline 1986 & $\begin{array}{c}\text { Addis Ababa/ } \\
\text { Harar }\end{array}$ & 276 & 13 & Prospective & 17 \\
\hline 1989 & Sidamo & 104 & 3.8 & Cross-sectional & 18 \\
\hline 1994 & Addis Ababa & 167 & 7.2 & Cross-sectional & 20 \\
\hline $1994 / 5$ & Harar & 252 & 17.9 & Cross-sectional & 21 \\
\hline 1998 & Arsi & 176 & 3.3 & Cross-sectional & 24 \\
\hline 2001 & Addis Ababa & 103 & 3.7 & Cross-sectional & 25 \\
\hline 2001 & Bahir Dar & 76 & 1.3 & Cross-sectional & 26 \\
\hline 2002 & Hosanna & 27 & 7.4 & Cross-sectional & 27 \\
\hline $2004 / 5$ & Addis Ababa & 73 & 27.4 & Cross-sectional & 29 \\
\hline $2004 / 5$ & Addis Ababa & 173 & 10.4 & Cross-sectional & 30 \\
\hline
\end{tabular}

In 1985 a study was carried out in Addis Ababa and Harar, involving all the TB centers, in $276 M$. tuberculosis isolates who had never taken any previous ant-tuberculosis chemotherapy. The prevalence of primary drug resistance was $15.2 \%(42 / 276)$. Of the 42 resistant isolates; 8 were resistant to three drugs; 31 to two drugs (in both instances, combination of INH, STM, THA and RMP); 23 were resistant to a single drug. All strains were found to be sensitive to EMB and PZM. RMP resistance was observed in $1 \%$ of the isolates from Addis Ababa, not Harar (Table-5 \& 6). ${ }^{17}$

In 1987 a cross sectional study was done in Sidamo regional hospital to assess primary resistance of 104 isolates of tubercle bacilli. The result showed that resistance to one or more ant- TB drugs was found to be 7.6\%. Two strains (1.9\%) showed resistance to INH and STM each. Four strains $(3.8 \%)$ showed double drug resistance to the same drugs $(\mathrm{INH}+\mathrm{STM})$. None were resistant to THA, RMP and EMB (Table-1). ${ }^{18}$

In 1993/94study was done in 107 strains isolated from retreatment cases of tubercle bacilli from Addis Ababa TB demonstrating and training center to determine acquired drug resistance and it was found that the prevalence of resistance to one or more of the first line drugs was about $50 \%$; $44 \%$ was resistant to INH, $28 \%$ to STM, $12 \%$ to RMP and 2\% to EMB; $19 \%$ was resistant to INH+STM, $8 \%$ to INH+RMP, and $4 \%$ to INH+RMP+STM. MDR was $12 \%$. All MDR strains were susceptible to amikacin, ciprofloxacin, ethambutol, ethionamide and clofazimine (Table-4, 6\& Fig-1) ${ }^{19}$

A study was done in 1994 in Addis Ababa (including all hospitals, health centers and six of the nine clinics in Addis Ababa) with 167 isolates of $M$.tuberculosis to assess the susceptibility of these strains to the anti-TB drugs. Of the 167 isolates $84.4 \%$ (141/167) showed no resistance to any drugs tested. Overall primary resistance involving one or more drugs was found to be $15.6 \%$ (26/167); primary resistance to two or more drugs was $7.2 \%(12 / 167)$ (Table-6). When each drug was considered, the highest rates of resistance was observed for STM (10.2\%) and INH (8.4\%), followed by THA $(6 \%)$ and RMP (1.8\%). Resistance to INH+THA was
$2.4 \%, \mathrm{STM}+\mathrm{THA}, \mathrm{RMP}+\mathrm{INH}, \mathrm{RMP}+\mathrm{STM}$ was $0.6 \%$ each. Resistance to EMB was nil. MDR was low $(0.6 \%)$ (Fig-2). ${ }^{20}$

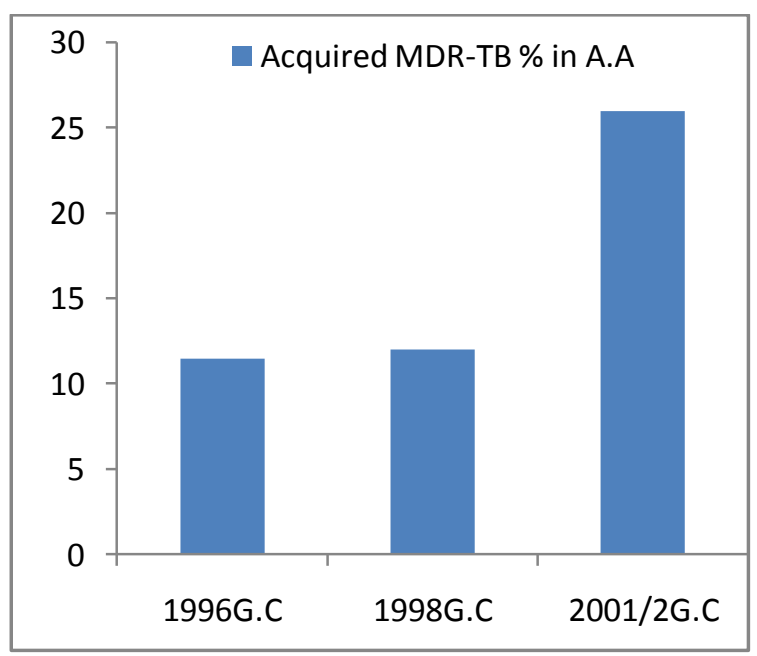

Figure 1: PERCENTAGE ACQUIRED MDR-TB IN ADDIS ABABA

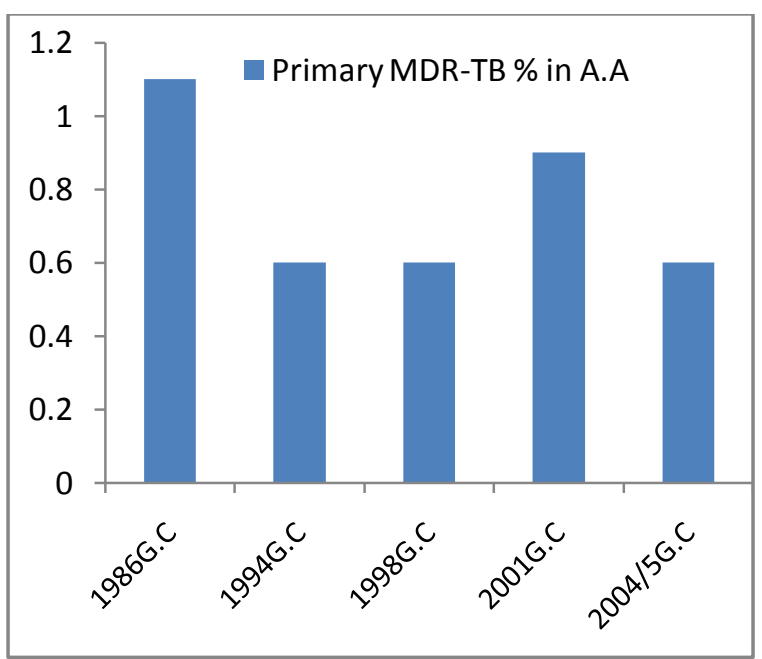

Figure 2: PERCENTAGE PRIMARY MDR-TB IN ADDIS ABABA 
In 1994/95 a cross sectional study was done to determine the initial and acquired resistance of 338 isolates of $M$ .tuberculosis in Harar TB center. The overall prevalence of resistance to one or more anti-TB drug was $37.3 \%$ (126/338). Initial resistance was $32.5 \%(82 / 252)$ while that of acquired resistance was $51.2 \%$ (44/86). Primary resistance to INH was $21.4 \%, 20.2 \%$ to STM, $1.6 \%$ to RMP, $6.3 \%$ to THA and $0.4 \%$ to EMB. Acquired resistance to INH was found to be $44.2 \%$ followed by STM $31.4 \%$, THA $8.1 \%$, RMP $5.8 \%$ and EMB $0 \%$ (Table-1\& 2). ${ }^{21}$

A study was done in 1995/6 in Addis Ababato assess the acquired resistance of 113 isolates of tubercle bacilli from Addis Ababa patients to first line, second line and experimental drugs. Of the 113 isolates $47 \%(53 / 113)$ were resistant to INH, $31 \%(35 / 113)$ to STM, $11.5 \%$ (13/113) to RMP, and 2.6\% (3/113) to EMB. All isolates resistant to RMP were MDR isolates. Most MDR isolates $(9 / 13)$ were susceptible to STM and all were susceptible to EMB. ${ }^{22}$ Among the 28 isolates resistant to the four first line drugs, 96\% (27/28) were resistant to clarithromycin, 96\% (27/28) to THA, 64\% (18/28) to cycloserine \& PAS (para-amino salicylic acid) and $36 \%(10 / 28)$ to rifabutin. Twenty one $(84 \%)$ out of 25 isolates resistant to first line drugs was susceptible to amikacin, ciprofloxacin, clofazimine, and ethionamide. MDR was seen in $11.5 \%$ $(13 / 113)$ of the isolates. Seven of these MDR isolates were isolated from chronic excreters (patient who remain acid fast smear positive after completing a retreatment regimen. ${ }^{23}$ Four from cases with relapse (who were cured in the past but again have active TB), ${ }^{23}$ one from a defaulter (patient who discontinued treatment for at least one month) ${ }^{11}$ and one from a patient who was smear positive after five months of treatment (Table-2).

In 1997/98 a study was done in Arsi zone to determine primary and acquired resistance of 195 isolates of $M$. tuberculosis. Among 195 isolates, 175 (90.2\%) never had prior treatment to anti-TB drugs and 19 (9.7\%) had had prior treatment to anti-TB drugs for a mean duration of one month. The overall resistance level to one or more anti-TB drugs was $38 / 195(19.5 \%)$. Of the 176 isolates $32 / 176(18.2 \%)$ was primary resistance and $6 / 19(31.6 \%)$ was acquired resistance. Primary resistance to INH and STM were $2.3 \%$ and $11.4 \%$ respectively. Of the 19 patients who had prior treatment resistance to INH was $5.3 \%$ and $10.5 \%$ to STM. Primary and acquired MDRTB was nil. Mono-resistance to RMP and EMB was nil (Table-1 \&2). ${ }^{24}$

In 2001 a study was done in Addis Ababa at Tikur Anbesa hospital to assess acquired and primary drug resistance of 121 isolates of $M$. tuberculosis in patients with and without HIV infection. In total, 17 of 121 isolates $(14.0 \%)$ were resistant to one or more of the anti-tuberculosis drugs. INH resistance was $8.3 \%$, STM $7.4 \%$, RMP $2.5 \%$, and EMB $1.7 \%$ (Table-1\&2). ${ }^{25}$

The study carried out in 2001, at two health institutions (felegehiwot hospital and Bahirdar health center) in Bahir Dar showed that of the 76 strains isolated from newly diagnosed patients, primary mono-resistance was highest to STM (14.5\%) followed by INH (2.6\%). In this study all isolates were susceptible to RMP and EMB. Primary resistance to any was found in $18.4 \%$ of new TB patients; and any primary resistance to STM was $15.8 \%$; $3.9 \%$ was to INH; to RMP was $1.3 \%$ and nil for EMB. The rate of primary MDR was $1.3 \%$ (Table-1, 5\&Fig2). ${ }^{26}$

The study done in Hosanna in 2002 showed that of the total 30 isolates; 8 (26.6\%) were resistant to one or more anti-TB drugs. Primary and acquired resistances were in 6 of the 27 strains $(22.2 \%)$ and in 2 of the 3 strains $(66.7 \%)$ respectively. MDR-TB was nil in both primary and acquired drug resistant cases. Drug resistances were observed in INH $(20 \%)$ and STM $(13.3 \%)$. All the strains were sensitive to RMP and EMB. Poly resistance involving only INH and STM was observed (Table-1 \&2). ${ }^{27}$

In 2001/2002 a study in St. Peter TB specialized Hospital was done to determine the anti-TB drug resistance among retreatment patients. Among the 84 isolates tested, resistance to at least one drug was observed in 45 $(53.6 \%)$ of them. The highest rate of resistance was observed against INH with $38.1 \%$ isolates resistant and $5.9 \%$ partial resistant. Resistance to RMP was found in $29.8 \%$ of the isolates. Nineteen percent of the isolates were resistant and $10.7 \%$ partially resistant to STM. Resistance and partial resistance to EMB was seen in $8.3 \%$ and $23.8 \%$, respectively. Twenty six point three percent of the isolates were MDR. Resistance to two drugs was observed in $13(15.5 \%)$, to three drugs in 11 $(13.1 \%)$ and four drugs in $12(14.3 \%)$ of the patients. Mono-resistance was observed in $9(10.7 \%)$ patients, of which 6 were against INH (Table-3, 4\&Fig-1). ${ }^{28}$

In 2004/2005 study was performed assessing the susceptibility of 73 isolates of $M$. tuberculosis taken from smear negative (37) and smear positive (36) patients visiting St. Peter TB Specialized Hospital. Of the 37 isolates, $29.8 \%$ (11/37) showed resistance to any of the drugs tested. Mono-resistance was found only for STM in 9 (24.3\%) isolates. Resistance to INH, EMB and RMP accounted for 1 (2.7\%) each. Resistance to two or more drugs was observed in 5/37 (13.5\%) strains. Resistance to any drug was observed in $27.4 \%$ (20/73) of the isolates. The resistance rate to INH, RMP, STM, and EMB was $5.5 \%$ (4/73), 1.4\% (1/73), 26\% (19/73) and $2.7 \%(2 / 73)$, respectively. Resistance to INH+STM was $26 \%(19 / 73), 1.4 \%(1 / 73)$ to INH+STM+ EMB. No MDR strains were observed in this study (Table-1, 5 \& 6). ${ }^{29}$

In 2004/2005 a study was conducted to assess the primary drug resistance in newly diagnosed smear positive TB patients visiting 19 health centers and 3 hospitals in Addis Ababa. Among the M. tuberculosis strains isolated from 173 patients, $21.4 \%$ were resistant to at least one drug; single drug resistance to STM was observed in $16.2 \%$, to INH in $13.3 \%$, to RMP in $1.2 \%$ and to EMB in $3.5 \%$ of the isolates. The prevalence of resistance to at least one drug was $15.7 \%$ and $23.7 \%$ among patients with and without HIV co-infection, respectively. The prevalence of resistance to more than one drug was $10.4 \%$ (Table-1, 5 \&6). ${ }^{30}$ 


\section{DISCUSSION}

As can be seen from the results described above, from different parts of Ethiopia, anti-TB drug resistance especially in the retreatment cases is increasing in spite of introduction of DOTS to different parts of the country. Mono resistance to INH and STM is increasing in very high speed with time. This leads to development of resistance to EMB and RMP (MDR-TB) when INH is given with one of these drugs in the continuation phase due to mono therapy. Increase in STM resistance also increases poly resistance that endangers the existing drugs (Table-1 and 2).

A high mono-resistance rate facilitates the emergence of MDR-TB ${ }^{31}$; emergence of MDR-TB facilitates extended drug resistance (XDR) (MDR-TB that is resistant to quinolones and also to any one of the injectable drugs; kanamycin, capreomycin, or amikacin). ${ }^{32}$ to occur. In previously treated patients in DOTS implementing areas, MDR-TB could emerge in a sequential manner; i.e., initial resistance to INH or STM is amplified to double STM and INH resistance; initial resistance to INH or RMP is amplified to double INH and RMP resistance and so on and finally to MDR-TB and XDR-TB. ${ }^{31,33}$ The rate of MDR-TB is increasing in spite of DOTS implementation in Ethiopia as can be seen from the figures specially acquired MDR-TB (Fig-1). In general resistance to the first line anti-tuberculosis is increasing with time as can be seen from the different studies done in Ethiopia. Patients with INH resistance receiving INH and EMB in the continuation phase will undergo EMB mono-therapy resulting in development of EMB resistance. EMB is a bacteriostatic drug with low efficacy that may not effectively prevent development of resistance to INH. Patients with INH resistance receiving INH and RMP in the continuation phase will undergo RMP mono-therapy resulting in development of RMP resistance that leads to MDR-TB.

Even though the number of patients involved, the method of sensitivity test, design of study, place of study, area of coverage etc., differ from one study to the other, the various studies carried out in various parts of Ethiopia at different time, showed that generally the danger of resistance to the existing anti-TB drugs is increasing which leads to shifting to the more expensive, more toxic, less effective, unavailable drugs and finally to untreatable and facing difficulty of controlling the disease.

The study done in 1978 showed high acquired resistance to INH (46\%), STM (46\%), and THA (29\%). ${ }^{15}$ All this resistance was suggested to come from treatment failure (could be from inadequate dose, non-compliance, inappropriate prescription, inappropriate combination) and relapse cases (the patient is obtained to be smear positive after he/she is declared cured of the disease).

The prospective study done in Harar and Addis Ababa in 1985 showed that the prevalence of primary resistance to one or more drugs was $15.2 \%$ which was comparable to the previous studies. ${ }^{16}$ Resistance to rifampicin was obtained from the strains isolated from Addis Ababa patients (but not from Harar) unlike similar strains (c) 2011-14, JDDT. All Rights Reserved isolated from the same area in the earlier studies. ${ }^{15}$ This could be due to the high resistance to isoniazid that was widely available in private and government health institutions, was quite generally prescribed alone or in combination unlikely to be effective by non- professional or untrained practitioners throughout the country. No resistance was encountered to ethambutol or pyrazinamide because these drugs were recently introduced in the treatment of TB in Ethiopia. In this study it was noted that thiacetazone, either alone or in combination, showed a low resistance rate, despite its wide use throughout Ethiopia. ${ }^{17}$

The study done in Sidamo regional hospital showed that the rate of resistance to one or more anti-TB drugs was $7.6 \%$ which was lower than the earlier recorded results in other area ${ }^{16,17}$ which in general was of the order of $15 \%$. In this area resistance rate to two combined drugs (INH+STM) and to three combined drugs (INH+STM+THA) was low and nil, respectively. This finding along with similar studies confirms the fact that primary drug resistance in general seems not to pose a major problem for the success of chemotherapy in tuberculosis. This is so because failure to respond to standard chemotherapy occurs in patients resistant to two or more drugs (low in this study) than in those resistant to one drug. ${ }^{23}$

The other study that showed high resistance to the antiTB drugs was the study done in Harar TB center in 1994/95. In this study the prevalence of primary drug resistance was $32.5 \%$ which was higher as compared to the previous studies done in this country that ranged between $7.5 \%$ and $15.2 \% .^{16,17}$ This high rate of resistance might be due to high defaulter rate, shortage of anti-TB drugs in government sector, availability of anti-TB drugs in open market which were smuggled from neighboring countries, unsupervised treatment and the practice of inappropriate prescriptions made by the private clinics in this area. War, displacement, drought and frequent population movements with disruption of health infrastructures might have contributed to the high prevalence resistance rate. Although initial/primary and acquired resistance to rifampicin were low $(1.6 \%, 5.8 \%$, respectively), no rifampicin resistance was reported previously in Harar region. ${ }^{17}$ This showed that resistance to rifampicin is increasing. In addition, the high resistance to isoniazid in both new and re-treatment cases of $\mathrm{TB}$ and the prevalence of MDR in 3.5\% of retreatment cases denotes that further delay in implementing DOTS and inadequate supervision may endanger the control of $\mathrm{TB}^{34}$ Initial resistance to streptomycin was higher when compared to the previous reports. ${ }^{15-18}$ This may be due to the wide spread abuse of streptomycin in this area, sputum smear examinations were not routine in many of the health facilities; therefore patients were started on standard regimen empirically. The frequent shortage of streptomycin that was observed has led to the increased cost of streptomycin that could not be afforded by many patients in this area. ${ }^{21}$ and streptomycin was prescribed to treat other infectious diseases too; that increase development of resistance to this drug. 
The study done in Arsi zone showed that the overall rate of resistance was $19.5 \%$ which was lower than the previous study done in Harar that was $37.3 \% .^{21}$ This was due to relatively well-organized control programme in this area. The acquired drug resistance was $31.6 \%$ that was lower than the previous studies done in Ethiopia. ${ }^{19}$, ${ }^{15},{ }^{21}$ This was because in this area DOTS were implemented, and the control program was relatively efficient. The primary resistance was obtained to be $18.2 \%$ whereas the earlier study in Harar showed $32.5 \% .{ }^{21}$ The accessibility of anti-TB drugs, supervised treatment, and the wide practice of treating tuberculosis patients in the health institutions with the recommended diagnosis, treatment and follow up procedures might have contributed to the low rate of primary drug resistance. Primary drug resistance rate observed to isoniazid in this study $(2.3 \%)$ was lower than the previous studies done in TB centers, which showed $12 \%$, $21.4 \%$ in 1981 and in 1994/5 respectively. ${ }^{16,21}$ This may reflect that patients coming to the health institutions were more likely to have not received prior anti-TB treatment as compared to the patients coming to tuberculosis centers. Single drug resistance to streptomycin was highest in this study. Overall the tendency of drug resistance to streptomycin seems increasing in recent years. ${ }^{16,20-21}$ This is thought to be related to the past wide spread use of streptomycin as antibiotic in the treatment of infectious disease other than tuberculosis. The absence of resistance to rifampicin alone and in combination with isoniazid, in this study, may probably indicate that these drugs were properly used in this area.

The study done in 2001/02 in Addis Ababa showed that $53.6 \%$ of the strains were resistant to the first line anti$\mathrm{TB}$ drug among the retreatment cases. ${ }^{28}$ The result of this study is comparable with a similar study on re-treatment cases in Addis Ababa that showed 50\% of the strains to be resistant to one or more of the first line drugs. ${ }^{19}$ Overall resistance to isoniazid was found to be $49.3 \%$. It tops the list compared to the other three drugs: rifampicin, streptomycin, and ethambutol. This figure is not very different from the results of the previous studies. This study however, showed an increase in resistance to rifampicin and ethambutol. The high rate of resistance to rifampicin could be associated with a number of factors: previous availability of loose rifampicin and its extensive use for $\mathrm{TB}$ and other infectious diseases, non-compliance and single drug administration. It is possible that patients with HIV infection may have altered absorption (malabsorption) for rifampicin that might lead to the development of rifampicin resistance ${ }^{35}$ though the status of the patients of this study was not known. In this study MDR-TB was observed in $26.3 \%$ of the patients. This is relatively high compared with previous reports $3.5 \%^{21}$ and $12 \%^{19}$ among re-treatment cases (Fig-1). The reason for this high multi drug resistance could be due to the high rifampicin resistance which is increasing with time.

The study done in Addis Ababa pulmonary tuberculosis patients in 2004/05 showed that the overall resistance rate involving one or more drugs was $27.4 \%$ which was higher than those in the previous studies in Ethiopia (14-
$22.3 \%) .{ }^{17}, 20,25,36$ The resistance rate for isoniazid was $5.5 \%$ which is within the range $1.9 \%-21.4 \% .^{16-17,20-}$ ${ }^{21,25}$ The primary resistance rate for streptomycin was $26 \%$ which is higher than all studies done in Ethiopia from 1978-2005 G.C. this can be explained as streptomycin was widely in use for treatment of other bacterial infections and patterns of inadequate treatment of tuberculosis patients, either due to lack of drugs or poor compliance by patients (defaulters); both in turn selecting drug resistant mutant strains. Although rifampicin is used currently for the treatment of many other infectious diseases and sold all over Ethiopia, the level of resistance was still very low $(1.4 \%)$. The rate is slightly higher than the previous studies done in Ethiopia $(0-1.9 \%) .{ }^{17,20,24-25}$ Resistance to ethambutol $(2.7 \%)$ in this study is within the range $0 \%-6.3 \%{ }^{16,17,21}$ of the other studies done in Ethiopia.

From all the fifteen studies reviewed only two studies were done on anti-tuberculosis drug resistance among patients with and without human immunodeficiency virus (HIV) co-infection. From these studies, on comparison between HIV positive and negative patients, no association was observed between drug resistance among new cases and HIV co-infection. This could be failure to identify any association; because HIV coinfected patients with drug resistant TB might have died earlier than HIV negative patients with drug resistant TB. ${ }^{37}$ This phenomenon could also explain the higher proportion of drug resistance in HIV negative patients than in HIV positive patients $(23.8 \%$ vs $15.7 \%){ }^{38}$ Additional reasons could be that HIV positive patients with drug resistance might have been missed because they tend to be smear negative, default or die undiagnosed.

\section{LIMITATIONS OF THE STUDY}

The studies reviewed here were done in various parts of the country with varied climatic conditions, culture, understanding etc., at different period. Some of the studies included TB/HIV co-infection, but most of the studies do not. Different numbers of strains were isolated using various methods of isolation, sensitivity testing methods, including different areas of coverage and health institutions (tuberculosis centers, hospitals, health centers and clinics) were used in the studies reviewed.

\section{CONCLUSION and RECOMMENDATION}

The review of different studies carried out in various parts of Ethiopia showed that anti-tuberculosis drug resistance is increasing and becoming concern to patients, health professionals and to the population in general.

It is understandable that the management of MDR-TB cases is very difficult and might involve expensive drugs. The management of these cases mainly depends on the in-vitro susceptibility pattern of the infecting isolate to the first and second lines drugs. The availability of second line drugs in the free market could easily lead to the amplification of resistance and might even make the management, at a later time, more difficult case even to the emergence of XDR-TB. Therefore, this may not 
seem to be a priority to control programs in low-income countries like Ethiopia where HIV/AIDS prevalence is high. So this should be the time when MDR-TB should be properly addressed and managed when the cases are few, before it spreads and many people come up with primary MDR-TB. For this purpose, the development of new and cheap drugs is essential and could be done by screening drugs which are being used for other clinical conditions, by screening traditionally used medicines or by producing novel drugs that can inhibit multiplication of the resistant strains and their transmission to others.

In the studies done in Ethiopia it has been shown that ethambutol resistance is increasing but still low. This is an advantage that should be exploited in order to develop a regimen for the management of MDR-TB. This can be considered as an important finding since almost all MDR strains of $M$.tuberculosis isolated in Ethiopia are susceptible to ethambutol.

\section{REFERENCES}

1. Miller B and Schieffelbein C. Tuberculosis. Bull World Health Organ1998; 76: 141-143.

2. WHO report. Global tuberculosis control: Surveillance, Planning, Financing. Geneva, Switzerland, WHO/CDS/TB/2003. 316.

3. World Health Organization. Epidemiology. Global tuberculosis control: epidemiology, strategy and financing, 2009, pp. 6-33.

4. World Health Organization Report. Global tuberculosis control, 2008: surveillance planning and financing.

5. Federal Ministry of Health. Manual of Tuberculosis, Leprosy and TB/HIV prevention and control programme. Fourth edition, 2008, Addis Ababa, Ethiopia.

6. Centers for Disease Control and Prevention (CDC), Division of Tuberculosis Elimination. Core Curriculum on Tuberculosis: What the Clinician Should Know, $4^{\text {th }}$ edition, 2000.

7. Kumar Vinay, Abbas Abul K, Fausto Nelson,et al.tuberculosis. Robbins Basic Pathology,Saunders Elsevier, $8^{\text {th }}$ ed., 2007, 516522.

8. WHO. Treatment of tuberculosis: Guidelines for national programmes. Geneva, Switzerland. WHO/TB/1997. PP. 21-31.

9. Rom N.W and Garay S.M.Tuberculosis. Little Brown and company USA, 1996. pp. 92- 93.

10. Salyers A.A and Whitt D.D. Tuberculosis. In Bacterial pathogenesis: A molecularapproach. AS press. Washington D.C., 1994. pp. 307-321.

11. WHO. Guidelines for surveillance of drug resistance in tuberculosis: WHO/TB/1994. 178. Geneva.

12. Geoffrey Marshall, C. Cameron, G.S. Wilson, et al. Streptomycin treatment of pulmonary tuberculosis. British Medical Journal 1948;2 (4582): 769-82.

13. Wang J.Y, Hsueh P.R, Jan I.S, et al. Empirical treatment with a fluoroquinolone delays the treatment for tuberculosis and is associated with a poor prognosis in endemic areas. Thorax2006;61 (10): 903-8.

14. WHO. Guidelines for the management of drug-resistant tuberculosis. Geneva, Switzerland. WHO/TB/1996. PP.5-15.

15. Pattyn s, Wolde K,Hadgu A.G,et al. Identification and drug sensitivity of tubercle bacilli from Addis Ababa, Ethiopia. Ethiop Med J1979; 17: 119-122.

16. Lemma E, Valdivia Alvarez J.A, Gebre-TsadikG. Drug sensitivity patterns of Mycobacterium tuberculosis isolates in Addis Ababa. Ethio Med J1984; 22: 93-96.

17. Wolde K, Lemma E and Abdi A. Primary resistance to the major anti-tuberculosis drugs in Ethiopia.Ethiop Med J1986; 24(1):158.
To manage and prevent the present trend in Ethiopia: national level anti-tuberculosis drug resistance survey, strict control of compliance of patients and health professionals, good infrastructure, strict rules and policies to prevent selling of drugs without prescription especially the second line drugs that are available in the open market, periodic drug surveillance, further study including HIV status, strong management of tuberculosis control with development of policies, public awareness about transmission and resistance development and its consequences, strengthening of laboratory capacity throughout the regions and urgent need for a newer, more effective vaccine that would prevent all forms of $\mathrm{TB}$; including drug resistant strains in all age groups and among people with HIV are recommended.

\section{ACKNOWLEDGMENT}

Using this opportunity I want to acknowledge Mekelle University for covering all my expenses during the study.

18. Lemma E, Niemi M, Lynton B, and Dubrie G. Bacteriological studies of tuberculosis in Sidamo Regional Hospital. Ethiop Med J1989; 27:147-149.

19. Abate G, Miorner $\mathrm{H}$, Ahmed O, et al. Drug resistance in Mycobacterium tuberculosis strains isolated from re-treatment cases of pulmonary tuberculosis in Ethiopia: susceptibility to first-line and alternative drugs.Int $J$ Tuberc Lung Dis 1998; 2:580-584.

20. Demissie M, Gebeyehu M, and Birhane Y. Primary Resistance to Anti- tuberculosis Drugs in Addis Ababa, Ethiopia. Int $J$ Tuberc Lung Dis 1997; 1: 64-67.

21. Mitike G, Kebede D, and Yeneneh H. Prevalence of antituberculosis drug resistance in Harar Tuberculosis Centre, Ethiopia. East Afr Med J 1997; 74 (3):158-61.

22. Abate G. In vitro susceptibility of clinical isolates of $M$. tuberculosis from patients in AA to first line, second line and experimental drugs, MSC THESIS 1996, Addis Ababa University, Ethiopia.

23. Canetti G, Fox W, Khomenko A,et al. Advances in techniques of testing mycobacterial drug sensitivity and the use of sensitivity tests in tuberculosis control programmes. Bull WHO 1969; 41: 21-43.

24. Gebeyehu M, Lemma E, and Eyob G. Prevalence of drugresistant tuberculosis in Arsi zone, Ethiopia. Ethiop J Health Dev 2001;15(1): 11-16.

25. Bruchfeld J, Aderaye G, Berggren Palme I, et al. Molecular epidemiology and drug resistance of Mycobacterium tuberculosis isolates from Ethiopian pulmonary TB patients with and without HIV infection. J ClinMicrobiol 2002; 40: 1636-43.

26. Zemedkun M. Primary drug resistance patterns of Mycobacterium tuberculosisisolates among new pulmonary tuberculosis patients inBahir Dar, Ethiopia. MSC THESIS 2003, Addis Ababa University.

27. GebreEndayelalu N. Drug resistance in $M$.tuberculosis in Hosanna, Ethiopia.MSC THESIS 2002, Addis Ababa University.

28. Woldemeskel D, Abate G, Lakew M,et al. Anti-tuberculosis drug resistance among retreatment patients seen at St. Peter Specialized tuberculosis Hospital. Ethiop Med J 2008; 46(3):219-25.

29. Desta K, Asrat D, Lemma E,et al. Drug susceptibility of Mycobacterium tuberculosis isolates from smear negative and positive pulmonary tuberculosis patients, Addis Ababa, Ethiopia. Ethiop J Health Dev2008; 22(2):212-215.

30. Asmamaw D, Seyoum B, Makonnen E,et al. Primary drug resistance in newly diagnosed smear positive tuberculosis 
patients in Addis Ababa, Ethiopia. Ethiop Med J 2008; 46(4):367-74.

31. Farmer P, Bayona J, Becerra M, et al. The dilemma of MDR-TB in the global era. Int J Tuberc Lung Dis 1998; 2: 869-76.

32. Gandhi N.R, Moll A and Sturm A.W. Extensively drug-resistant tuberculosis (XDR-TB): recommendations for prevention and control. WeeklyEpidemiological Record 2006; 81: 431- 43.

33. World Health Organization. Anti-tuberculosis drug resistance surveillance in the world. Report No.3. WHO/IUTALD global project on anti-tuberculosis drug resistance surveillance, 19992002. WHO/HTM/TB/2004.343. Geneva.

34. Laszlo A and De Cantor I.N. A random sample survey of initial drug resistance among TB cases in Latin America. Bull wldHlth Org 1994; 72(4): 603-610.
35. Peloqin C.A, Nitta A.T, Burman W.J,et al. Low anti-TB drug concentrations in patients with AIDS. Ann pharmacother 1996; 30: 919-25.

36. Eyob G, Gebrexabher H, Lemma E, et al. Drug susceptibility of mycobacterium tuberculosis in HIV-infected and uninfected Ethiopians and its impact on outcome after 24 months of followup. Int J Tuberc Lung Dis 2004; 8: 1388-1391.

37. Fischl M.A, Daikos G.L, Uttamchandani R.B, et al. Clinical presentation and outcome of patients with HIV infection and tuberculosis caused by multiple drug resistant bacilli. Ann Intern Med 1992; 117: 184-190.

38. Demissie M, Lemma E, Gebeyehu M, et al. Sensitivity to antituberculosis drugs in HIV positive and negative patients in Addis Ababa. Scand J Infect Dis 2001; 33: 914-9. 